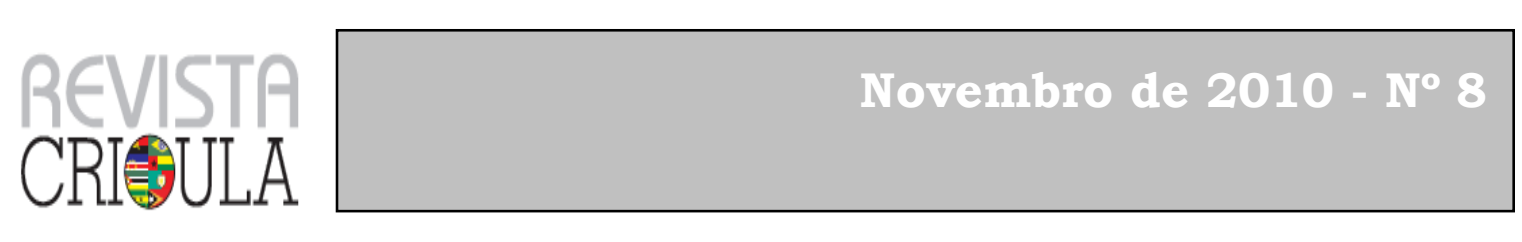

\title{
Literaturas e igualdade racial: \\ o compromisso de Tania Macêdo
}

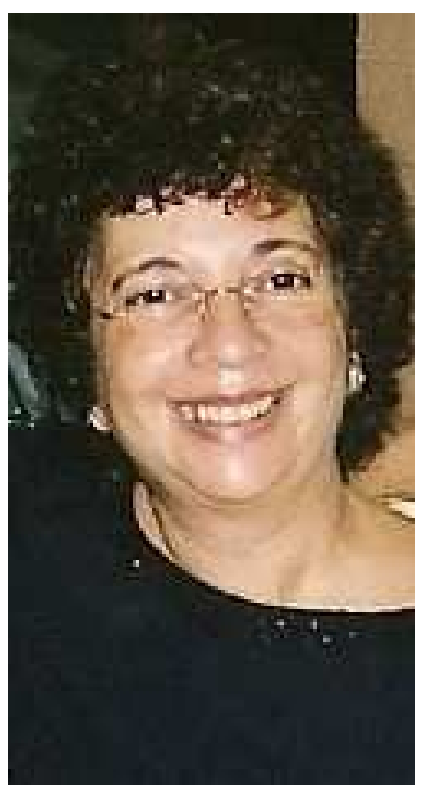

Tania Celestino de Macêdo é filha da capital paulista, onde vive sua família. Talvez por apreciar tanto o espaço imaginário das fronteiras, a professora resida nas proximidades da linha divisória entre Pinheiros e a Vila Madalena, dois tradicionais bairros da cidade de São Paulo, onde acontecem eventos culturais e circula parte da intelectualidade paulistana.

Graduada em Letras pela Faculdade de Filosofia, Letras e Ciências Humanas - a conhecida FFLCH da Universidade de São Paulo -, ingressou no Mestrado na mesma instituição, produzindo a dissertação Da Inconfidência à Revolução (trajetória do trabalho artístico de José Luandino Vieira), concluída no ano de 1979. Desde este trabalho acadêmico, Tania Macêdo não abandonou mais o empreendimento a que se propôs: a articulação de seu campo de pesquisa com as iniciativas pela igualdade racial e social nos dois lados do Atlântico de Língua Portuguesa. Para essa tarefa, procura artefatos culturais que contenham temáticas adequadas a esse tipo de reflexão e os elege como objetos de pesquisa.

O seu estudo sobre a produção literária do autor angolano Luandino Vieira, já na primeira pesquisa, demonstra o interesse que a

1 Professora, Doutora em Estudos Comparados de Literaturas de Lingua Portuguesa/USP. 
professora manteria, durante toda sua trajetória acadêmica, pelos elementos das culturas africanas, especificamente pela literatura.

Seu primeiro livro, bastante interessante, vem à luz em 1988, antes da conclusão de sua tese de doutorado, apresentando um estudo sobre Guimarães Rosa, publicado pela Editora Ática - São Paulo.

Após um rápido percurso por outras universidades, no ano seguinte, passa a lecionar na FCL - Faculdade de Ciências e Letras - na UNESP - Universidade Estadual Paulista "Júlio de Mesquita Filho" -, campus de Assis, no interior do Estado de São Paulo, onde desenvolve importantes trabalhos; entre estes, a coordenação do Acervo João Antonio e a Diretoria Científica do NUPE - Núcleo Negro de Pesquisa e Extensão - da faculdade, a partir de 2003. No núcleo, trabalha não somente com questões relativas à promoção da igualdade racial no Brasil e discussão de ações afirmativas, mas com a preparação de alunos para a compreensão das culturas negras e seus elementos no interior das literaturas africanas.

Conclui sua tese de doutorado um ano depois, como uma continuação das pesquisas que vinha desenvolvendo sobre Luandino Vieira, e inclui no trabalho muitos outros autores da literatura angolana, traçando um panorama sobre vários escritos literários produzidos nos anos da resistência aos assédios da polícia politica portuguesa - a PIDE - contra as populações dos chamados musseques casas construídas de areia - da cidade de Luanda.

E talvez venha daí o gosto da pesquisadora pelas fronteiras invisiveis, pelos "entre-lugares" e pela literatura das cidades, especialmente das capitais. A tese de doutoramento, intitulada Da fronteira do asfalto aos caminhos da liberdade (imagens de Luanda na literatura angolana

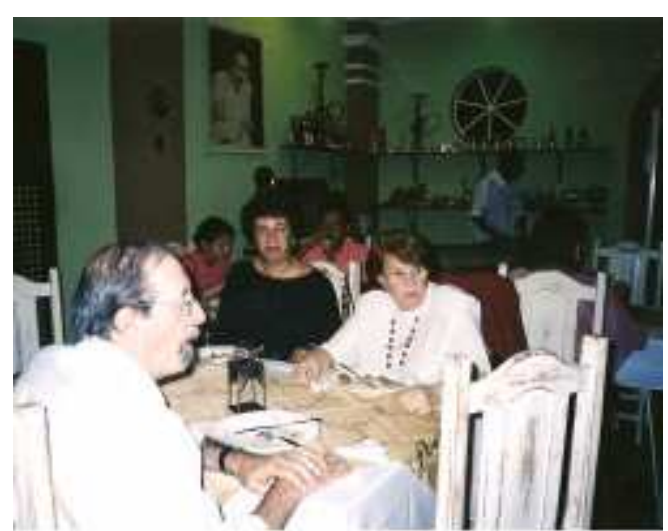

Da esq. para a dir.: Prof. Dr. Benjamin Abdala Jr. (Titular), Prof" Dra. Taria Macêdo e Prof" Dra. contemporânea), sob orientação do titular Dr. Benjamin Abdala Jr. - 
USP -, expõe um panorama amplo dos escritos literários, produzidos no espírito da consolidação da ficção angolana investida de um caráter com ideais libertários de nacionalidade.

Nessa conceituada instituição, desenvolve trabalhos acadêmicos importantes e atende no Programa de Pós-Graduação em Letras, orientando mestrados e doutorados. Concorre à vaga de LivreDocente no departamento de Literatura e defende a tese Uma cidade e sua escrita: a representação literária de Luanda, concluída em 2004, comemorada com muitos amigos.

Entre os livros publicados, além do estudo sobre Guimarães Rosa, destacam-se Cabeça feita (1992); Angola e Brasil: estudos comparados

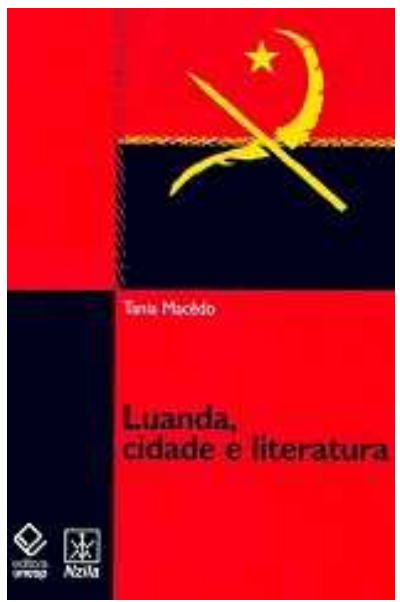
(2002) - em que expõe o resultado de uma pesquisa absolutamente inédita, extraída de documentos de época, intitulado "Sementes em chão de exilio" -; e publica também Luanda: cidade e literatura (2008). Em parceria com Rita de Cássia Natal Chaves, a amiga de sempre, a pesquisadora publicou Literaturas de Lingua Portuguesa - Angola (2007), que integra a coleção Marcos e Marcas -, o volume referente à Literatura desse país. Na mesma coleção, Tania publica, com o mesmo título, em parceria com Vera Maquêa, um volume que trata da literatura de Moçambique.

Além dos livros de sua própria autoria ou em parceria, organizou vários outros, em dupla com Rita Chaves, compondo uma bibliografia altamente significativa para os estudos das literaturas africanas de língua portuguesa: Portanto...Pepetela (2002, em Luanda); e, em 2009, a segunda edição deste livro - acrescentada de outros artigos e resenhas sobre os escritos do autor angolano -, naquela cidade e em São Paulo, simultaneamente; Literaturas em movimento: hibridismo cultural e exercício crítico (2003); Brasil - África: como se o mar fosse mentira (2006); e,

no mesmo ano, Marcas da diferença: as literaturas

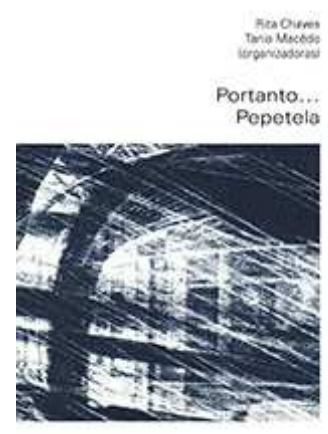


africanas de lingua portuguesa (2006).

Dentre as organizações, outras foram feitas a três mãos, como a coletânea de artigos e resenhas intitulada Boaventura Cardoso: a escrita em processo (2005), que reúne novamente Tânia, Rita e ainda, a angolana Inocência Mata, cujos textos traçam um percurso da escrita do autor angolano, como um panorama de sua evolução literária; e, ainda, A Kinda e a Misanga - Encontros brasileiros sobre a literatura angolana (2007), organização de Tania Macêdo, Rita Chaves e Rejane Vecchia, que conseguiram a proeza de reunir textos oriundos de várias instituições do país, de diversos estados brasileiros, somando esforços de pesquisadores do Arroio ao Chuí, em torno dos estudos das literaturas de língua portuguesa.

Publicou, ainda, importantes artigos resultantes de investigações científicas em periódicos especializados nacionais e internacionais, em países como Angola, Portugal e Estados Unidos, e mais de vinte trabalhos em Anais de Eventos.

Além de artigos, publicou capítulos de livros em Portugal, Angola, Moçambique, Bélgica e Brasil

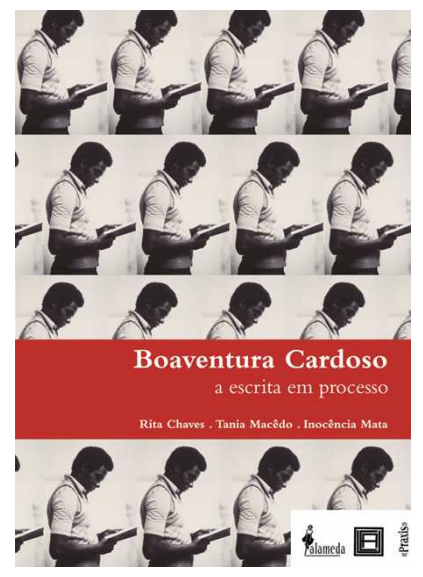
e, ainda, cerca de dezessete textos em revistas e jornais de notícias diversas. Do estudo de expressões culturais, como a capoeira e o carnaval, ao encantamento do poeta e estudos de crônicas, a pesquisadora faz incursões por vertentes diversas da cultura brasileira e angolana, mais especificamente, de forma implícita, busca também uma abordagem das mestiçagens que originaram essas formas culturais.

Da atuação no ensino de graduação, ministrado na UNESP campus de Assis -, onde lecionava Literatura portuguesa e africana, aposentou-se das atividades nesse nivel, em 2004, e passou a atender exclusivamente à FFLCH, até 2005. Quanto à Pós-Graduação, continuou oferecendo disciplinas na USP, no Programa de PósGraduação em Estudos Comparados de Literaturas de Língua 
Portuguesa, onde ministra a disciplina Literaturas Africanas de Língua Portuguesa I; e, no mesmo ano, iniciou a docência também no Programa de Pós-Graduação em Literaturas de Língua Portuguesa da UAN - Universidade Agostinho Neto, em Luanda - Angola -, ofertando a disciplina Literatura Brasileira.

Em sua atuação como professora, sempre esteve ao lado de seus alunos, tanto na graduação, quanto no da pós-graduação, promovendo encontros e situações informais que aproximassem as pessoas. Nessa função, procurou orientar de maneira que as pessoas percebessem a importância dos países africanos de língua portuguesa no cenário internacional, bem como nas relações que se estabeleciam entre as culturas daqueles países e as formas culturais presentes nos modos de viver e pensar do povo brasileiro. Por isso, costumava promover eventos que aproximavam os alunos e a professora, com o objetivo de estreitar os laços amistosos.

Empenhada na divulgação da cultura afro-brasileira, das políticas públicas para negros e mestiços, oferecia aos alunos a cultura dos países, não somente por meio da literatura, mas usando, ela mesma, o vestuário típico de países africanos, apresentando artesanatos característicos desses lugares - como a sua coleção de estátuas de mulheres negras (originais), kindas, capulanas, etc. - que levava para a sala de aula e apresentava como relíquias das manifestações culturais originárias das nossas.

No campo da orientação, Tania parece ter conquistado um conhecimento raro: como instigar seus alunos e desafiá-los para que continuem na pesquisa de temas tantas vezes dificeis de serem tratados, muitas vezes, polêmicos.

Essa facilidade para despertar curiosidades faz com que possa empreender projetos de pesquisa muito interessantes.Por outro lado, oferece ao orientando certa liberdade de pensamento que permite ao aluno trilhar caminhos próprios. Por isso, os trabalhos de seus orientandos, tantas vezes, apresentam ideias originais e diversas, amplificando o campo de estudos e pesquisas abertos pela orientadora. 
Simultaneamente, atendia, desde 1998, ao Programa de PósGraduação em Estudos Comparados de Literaturas de Lingua Portuguesa da FFLCH -, com a disciplina Uma cidade, várias leituras, a qual ainda ministra, onde enfatiza a literatura produzida em Angola, entre outras de lingua portuguesa.

Desde 2005, atua como avaliadora dos cursos de Letras das instituições de ensino superior do INEP - Instituto Nacional de Estudos e Pesquisas Educacionais, órgão do MEC - Ministério de Educação e Cultura.

Envolvida com grande número de pesquisas e produções, destaca-se na produtividade acadêmica dos indicadores do CNPQ Conselho Nacional de Pesquisa.

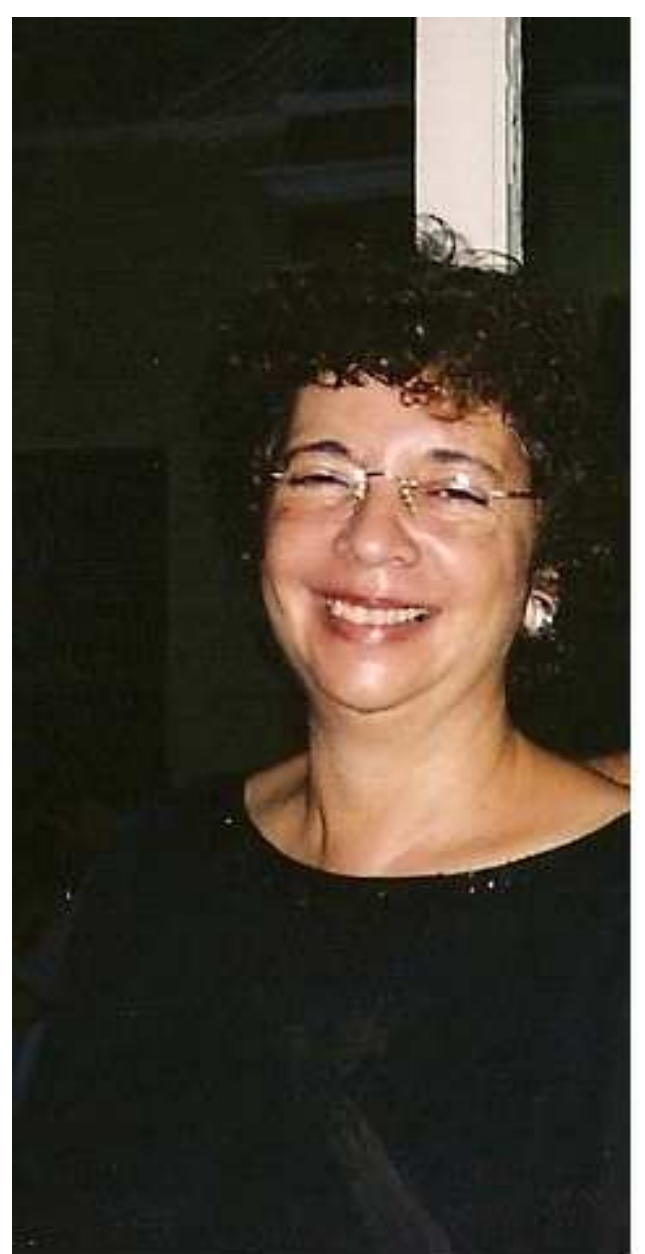

Foto: MAHTOLVAHI, R. M.
Desenvolveu alguns trabalhos importantes de pesquisa, a exemplo de Malandragens transoceânicas: aventuras do anti-herói nas literaturas de Angola e do Brasil (2001-2003), cujo projeto compara os anti-heróis de narrativas do escritor angolano José Luandino Vieira e os do brasileiro João Antônio, destacando a importância da cidade na existência das personagens; Sob o signo $d a$ crueldade: literatura, cidades $e$ violência (2003 - 2004), em que tratou de pesquisar sobre as representações das personagens marginais nas narrativas urbanas, resgatando 0 papel dessas figuras e suas relações com o quotidiano violento das cartografias urbanas.

Em 2006 inicia outro projeto: Os anos de pólvora: ficção, história e memórias em narrativas de Angola e Moçambique, em que propõe o 
estudo de textos memorialísticos desses países africanos de lingua portuguesa, enfatizando o estudo dos heróis em escritos dos dois países, destacando as formas de sua representação no cenário de um país em conflito; e, em 2010 dá início ao projeto $A$ construção dos inimigos: uma semântica do colonialismo português e sua apropriação pela literatura, ainda em andamento, em Portugal, no qual procura desentranhar dos escritos de documentos diversos a semântica que propiciou a construção da imagem do inimigo do império português, nos anos do regime salazarista, como propaganda do colonialismo. Os últimos dois projetos de pesquisa continuam em execução.

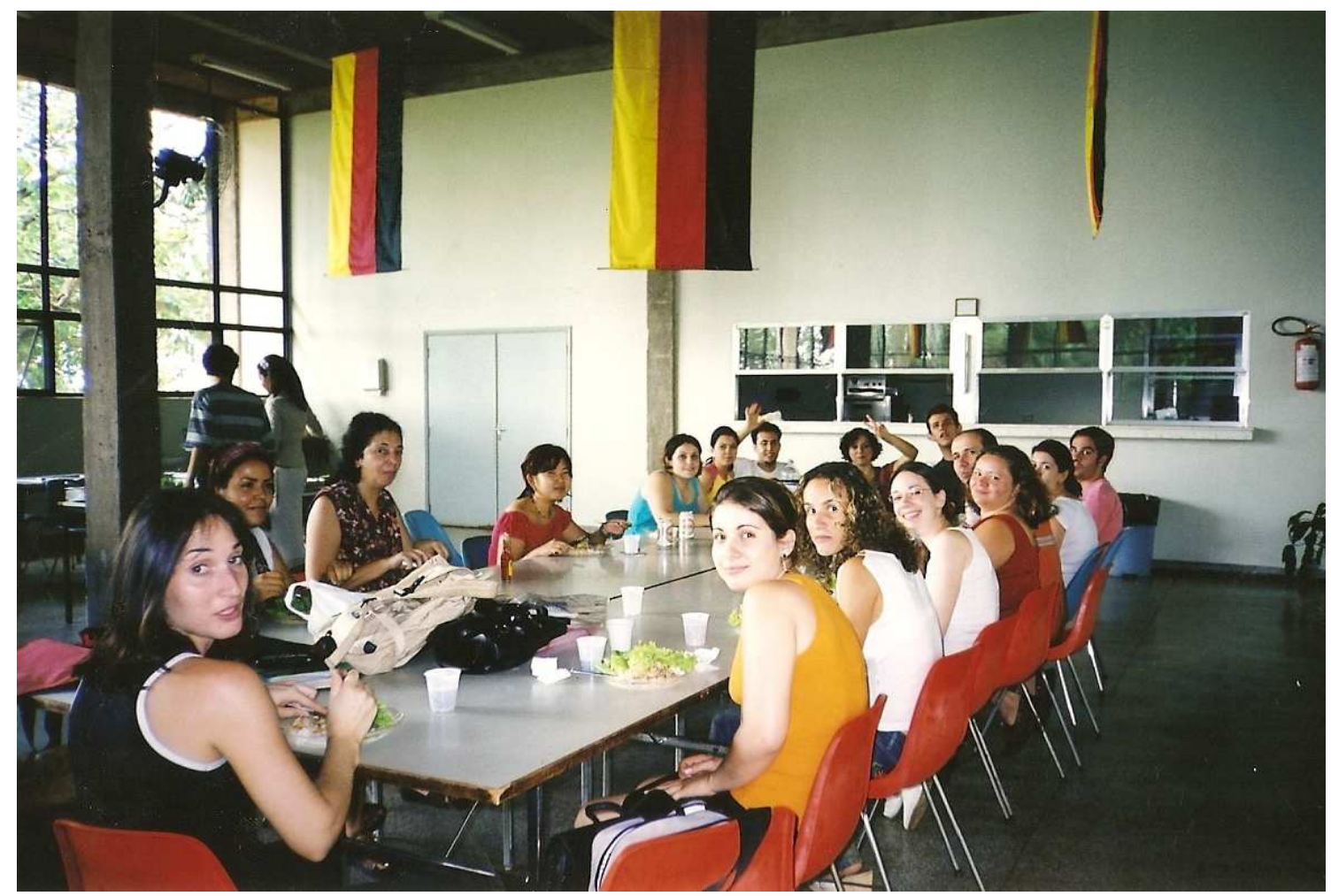

Almoço angolano - promovido pela professora, com prato típico, reunindo os alunos da disciplina de Literaturas Africanas de Língua Portuguesa. Foto: MANTOLVANI, R. M. - UNESP - Assis, 2002.

Por essa facilidade, orientou sete trabalhos de iniciação científica, dezessete dissertações de mestrado e seis teses de doutorado.

Tania continua, dessa maneira, dedicando sua vida à pesquisa e à docência, apenas dando sequência a uma vida que parece ter sido traçada exclusivamente no sentido da descoberta.

Ao atuar na coordenação de projetos que visam transformar situações de opressão em caminhos para a reflexão e, quem sabe, para 
a liberdade, pelo reconhecimento e valorização dos elementos culturais de matriz africana que povoam nossa própria cultura, é que ela contribui para os novos rumos da pesquisa nos dois lados do Atlântico Sul. 